\title{
Electrodeposition of Platinum Catalyst from Ionic Liquids
}

\author{
J. Diederich ${ }^{\mathrm{a}}, \mathrm{S}$. Martens ${ }^{\mathrm{b}}$, L. Asen ${ }^{\mathrm{b}, \mathrm{c}}$, and O. Schneider ${ }^{\mathrm{b}}$ \\ a Physics Department, Technical University of Munich, Garching 85748, Germany \\ ${ }^{\mathrm{b}}$ Department of Informatics, Technical University of Munich, Garching 85748, Germany \\ ${ }^{c}$ Department of Chemistry, Technical University of Munich, Garching 85748, Germany
}

The deposition of platinum from precursors dissolved in the ionic liquid 1-methyl-1-octylpyrrolidinium bis(trifluoromethylsulfonyl) imide (OMP-TFSI) was the main scope of this study. Boron doped diamond (BDD) and Au electrodes on quartz resonators were used as the substrates. A typical Pt deposition on BDD and Au was accomplished by applying short electrical pulses followed by relaxation phases for different duration in order to find optimal deposition conditions. In order to prove whether $\mathrm{Pt}$ was deposited on the electrode, samples were cycled in $0.1 \mathrm{M} \mathrm{H}_{2} \mathrm{SO}_{4}$ after deposition. In addition to electrochemical parameters, in the experiments on $\mathrm{Au}$, the electrochemical quartz crystal microbalance permitted to monitor directly changes in the resonance frequency and damping associated with the $\mathrm{Pt}$ ion reduction processes.

\section{Introduction}

Both battery and fuel cell electric vehicles are important building blocks for the transition to sustainable transportation (1). Fuel cell vehicles have not yet reached a wide market penetration due to high cost and limited refueling infrastructure. One important factor is the sluggish kinetics of the oxygen reduction reaction (ORR) at the cathode side causing a high overpotential. Therefore, in order to improve the energy efficiency and to deliver the electric power needed, a high amount of Pt catalyst is required, becoming a major cost factor (1-6). There are several approaches to battle the large amount of Pt catalyst: to enhance the utilization of Pt by different nanostructuring approaches (7), to nano-engineer shape-selected nanoparticles in order to generate particularly active surface sites (8), to take advantage of catalyst-support interactions $(9,10)$, to develop entirely Pt-free catalysts and especially to use highly active Pt alloys (11-17). Alloying can alter the interaction with the ORR intermediates and in turn enhance the overall reaction rate, mainly due to ligand and strain effects (18-23). The design of an actual catalyst layer for a proton exchange membrane fuel cell is an art in itself. These layers must enable operation over a wide range of current densities of up to $2 \mathrm{~A} \mathrm{~cm}^{-2}$ or more with minimum degradation. In particular, both catalyst and support must be chemically and structurally stable. The catalysts need a high intrinsic activity, which is normally assessed at $0.9 \mathrm{~V}$ cell voltage, but the catalyst layer also needs to provide excellent mass transport properties to supply large currents. Alloys between Pt and rare earth metals attracted a lot of attention because they combine both a high activity at $0.9 \mathrm{~V}$ and excellent stability during cycling $(18,21,24-32)$.

The development of inexpensive fuel cells requires preparation of catalysts by scalable and inexpensive methods. For normal Pt-transition metal alloys, this can be accomplished 
by chemical methods like the solvothermal reduction method $(33,34)$. However, the rare earth elements are extremely sensitive towards air and moisture and their standard potentials are very low. This makes bottom-up synthesis of alloy nanoparticles based on rare earth metals difficult and almost not possible from aqueous solutions. Recently, though, a top-down approach working in aqueous electrolyte has been reported (35).

Electrodeposition is an effective pathway for the preparation of Pt nanoparticles. By choosing suitable electrolysis conditions one can control the morphology and the size of the particles. Electrodeposition of pure Pt can be accomplished in aqueous solutions (3638). However, aiming at Pt alloys with very reactive alloying elements like the rare earth elements requires a non-aqueous approach. Especially suitable are ionic liquids (ILs). Several studies reported the electrodeposition of rare earth metals from ILs (39-42). The main advantages of ILs are a wide electrochemical window, low flammability, a nearly non-existing vapor pressure, and often low toxicity (43). However, electrochemistry in ionic liquids is very different from aqueous electrochemistry (43). It is known that the IL/solid interface shows a very complex multilayer structure that can hinder metal cations from approaching the electrode surface (44-47) and prevent the deposition of metals even at potentials where the process should take place (44). One of the approaches to disturb these layers and facilitate the deposition is the use of additives or the presence of impurities (48).

The electrodeposition of Pt using standard Pt precursors from several ILs has been reported $(6,49-52)$. He et al. deposited Pt from two imidazolium-based ionic liquids, 1-

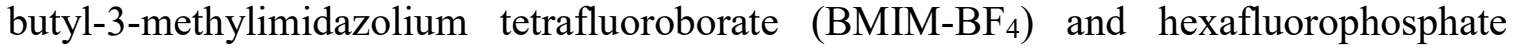
$\left(\mathrm{BMIM}_{-} \mathrm{PF}_{6}\right)$ (49). The morphology of the obtained deposits was different compared to deposits from aqueous solutions. At electrodeposition potentials of $-1.5 \mathrm{~V}$ vs $\mathrm{Ag} / \mathrm{AgCl}$, in both ILs fairly uniform and dense shiny deposits were obtained on a glassy carbon electrode from hexachloroplatinic acid hydrate $\mathrm{H}_{2} \mathrm{PtCl}_{6} \times 6 \mathrm{H}_{2} \mathrm{O}(18 \mathrm{mM})$, with nanoparticles (NPs) of less than $100 \mathrm{~nm}$ in diameter. In 2010, the deposition of Pt was reported from $50 \mathrm{mM} \mathrm{PtCl}_{2}$ in the two ionic liquids 1-butyl-1-methylpyrrolidinium dicyanamide (BMP-DCA) and bis(trifluoromethylsulfonyl)imide (BMP-TFSI) and mixtures thereof (51). No coupled oxidation wave was detected in the recorded CV indicating that the deposited Pt could not be reoxidized from the electrode surface. In the same year, $\mathrm{Yu}$ and co-authors obtained $\mathrm{Pt}$ nanoparticles from $20 \mathrm{mM} \mathrm{H}_{2} \mathrm{PtCl}_{6}$ in $\mathrm{BMIM}^{-\mathrm{PF}_{6}}$ (52). NPs with a size of $3.5-4 \mathrm{~nm}$ were electrochemically synthesized when rather low overpotentials were applied $(-1.8 \mathrm{~V}$ vs $\mathrm{Ag} / \mathrm{AgCl}$ ), indicated by a change in the electrolyte color and proved by XPS. At higher applied overpotentials ( $-2.8 \mathrm{~V}$ vs $\mathrm{Ag} / \mathrm{AgCl}) \mathrm{Pt}$ NPs with a uniform size of about $100 \mathrm{~nm}$ were deposited on an ITO substrate and no color change was detected in the IL. D. Zhang and co-authors deposited $\mathrm{Pt}$ from $70 \mathrm{mM} \mathrm{K}_{2} \mathrm{PtCl}_{6}$ in N,N-diethyl-N-methyl-N-

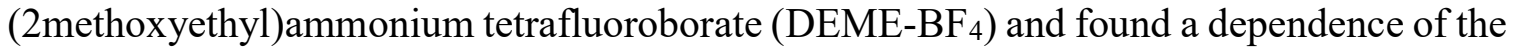
deposition mechanism on the applied potential (50). At larger overpotentials the $\mathrm{Pt}$ deposition takes place via the four electron reduction of $\left[\mathrm{PtCl}_{6}\right]^{2-}$ and at lower overpotentials via a disproportionation reaction of $\left[\mathrm{PtCl}_{4}\right]^{2-}$. The overpotential also strongly influenced the morphology of the obtained deposits. At both applied potentials small particles $1-2 \mathrm{~nm}$ in size formed initially which then grew further. At lower overpotentials, this resulted in uniform particles of about $10-50 \mathrm{~nm}$ covering compactly the electrode surface. At higher overpotentials, two groups of larger particles were formed, 50 - 100 and 100 - $200 \mathrm{~nm}$ in size, irregularly covering the glassy carbon surface. 
Recently, we successfully electrodeposited gadolinium from the IL BMIM DCA, but several attempts to synthesize Pt from the same IL failed (53). Therefore, we decided to take a step back and systematically study the electrodeposition of Pt from the IL 1-methyl1-octylpyrrolidinium TFSI (OMP-TFSI), and then gradually do the transfer to an electrolyte system from which also Gd can be deposited by using mixed electrolytes. In previous work, we had demonstrated deposition of $\mathrm{Pt}$ from a $\mathrm{H}_{2} \mathrm{PtCl}_{6}$ precursor dissolved in OMP-TFSI on highly oriented pyrolithic graphite (HOPG) at room temperature (6). In the current work, we employed boron doped diamond (BDD) and Au electrodes on quartz resonators for the electrochemical quartz crystal microbalance technique (EQCM) as substrates, and increased the working temperature to $60{ }^{\circ} \mathrm{C}$.

\section{Experimental}

All glass and Teflon ware in this study was cleaned prior to use first in alkaline cleaning baths and then in Caro's acid, followed by boiling in ultrapure water (Milli-Q Integral 3). All experiments were carried out in three-electrode setups containing a working (WE), a counter (CE) and a reference electrode (RE). As WE boron doped diamond substrates (BDD on Silicon, NeoCoat, $14 \times 14 \mathrm{~mm}$ ) or one of the gold electrodes of quartz resonators (KVG, Quarztechnik Daun) were used. The BDD substrates were cleaned and activated prior to use by cycling in $0.1 \mathrm{M} \mathrm{H}_{2} \mathrm{SO}_{4}$ (prepared from concentrated sulfuric acid $(96 \%)$ dissolved in ultrapure water) in a large three electrode glass cell equipped with glass tubes for Ar purging. The cleaning procedure comprised 100 cycles between -1.2 and $1.5 \mathrm{~V}$ vs. a $\mathrm{Hg} / \mathrm{Hg}_{2} \mathrm{SO}_{4}$ reference electrode ( $\mathrm{E}_{\text {ref }}=660 \mathrm{mV}$ vs. Standard Hydrogen Electrode) at 100 $\mathrm{mV} \mathrm{s}^{-1}$ in $0.1 \mathrm{M} \mathrm{H}_{2} \mathrm{SO}_{4}$. Cathodic activation was achieved by carrying out 200 cycles in the potential range of -1.5 to $0 \mathrm{~V}$ vs $\mathrm{Hg} / \mathrm{Hg}_{2} \mathrm{SO}_{4}$. For EQCM, one of the gold electrodes of $10 \mathrm{MHz}$ quartz resonators (KVG GmbH, $10 \mathrm{MHz}$ AT cut, $14 \mathrm{~mm}$ diameter, keyhole-shaped optically polished $\mathrm{Au}$ electrodes on $\mathrm{Cr}$ adhesion layer on each side) served as a working electrode and the other one was electrically isolated from the solution by Simriz-O-Rings (Freudenberg). Pt wires (99.99\%, MaTeck $\mathrm{GmbH}$, cleaned by annealing in a propene gas flame) were employed as counter and quasi-reference electrodes. All deposition experiments were carried out in an Argon filled glovebox (MBraun UNIlab plus eco). Electrolytes used were either $50 \mathrm{mM}$ Chloroplatinic acid hexahydrate $\left(\mathrm{H}_{2} \mathrm{PtCl}_{6} \times 6 \mathrm{H}_{2} \mathrm{O}\right.$, $99.995 \%$, Sigma Aldrich) or Platinum tetrachloride $\left(\mathrm{PtCl}_{4}, 99,99+\%\right.$, Alfa Aesar), dissolved in OMP-TFSI (99\%, iolitec). The IL was dried prior to use by heating it to 100 ${ }^{\circ} \mathrm{C}$ under vacuum under constant stirring with a magnetic stirring bar. A small volume of about $0.7 \mathrm{ml}$ of electrolyte was filled into a custom-made Teflon cell embedded in a steel jacket permitting temperature control. This was achieved by connecting a Julabo 600F thermostat placed outside the glovebox filled with Julabo Thermal H10 silicon oil via tubing and a feedthrough. The electrochemical measurements were controlled by a Solartron SI1287 electrochemical interface using home-made software. An Agilent E5100A network analyzer (NA) was used for the measurements of the electrical admittance spectra of the quartz resonators in the vicinity of their resonance frequency, in parallel to the electrochemical measurements. The resonance frequency of the quartz $f_{R}$ and its damping $w$ were determined by fitting the real part of the admittance spectra to a Lorentz function. The deposition of a layer on the Au electrode causes the resonance frequency to decrease. From the resulting changes $\Delta f_{R}$, the mass of the layer can be determined via the Sauerbrey equation (54), provided that it is a smooth layer rigidly attached to the surface, and no changes in the viscous properties of the electrolyte close to the surface occur. This 
is typically the case when the absolute change in $f_{R}$ is much larger than the one in $w$ (55). The electrochemical deposition of Pt was studied by cyclic voltammetry (CV) in different potential ranges. The deposition of a larger quantity of $\mathrm{Pt}$ was then targeted by the application of pulsed electrodeposition (PED). The deposition potentials were chosen according to the cathodic peak positions, and the OFF potentials from the anodic sweep of the CVs. The pulse lengths were varied to find optimal deposition parameters. After the deposition, the samples were rinsed with isopropanol and water in order to remove the electrolyte and residues of the precursors. The samples were then transferred to the large glass cell outside the glove box. In order to prove the presence of Pt particles on the electrode, the samples were therein cycled in $0.1 \mathrm{M} \mathrm{H}_{2} \mathrm{SO}_{4}$ at a scan rate of $100 \mathrm{mV} \mathrm{s}^{-1}$ under Argon for obtaining the characteristic Pt voltammograms. In addition, estimates of the electrochemically active surface area (ECSA) were determined similar to the procedure in Ref. (56), even though the lower cutoff potential was in most experiments not low enough to permit truly quantitative determination of the Pt surface area.

\section{Results}

\section{Electrochemical Deposition of Pt on Boron Doped Diamond}

Deposition from Hexachloroplatinic Acid. In our previous studies, Pt had been deposited from a solution of $\mathrm{H}_{2} \mathrm{PtCl}_{6}$ in OMP-TFSI. This precursor is not suitable for the deposition of a Pt-Gd alloy, as it does contain crystal water. However, it serves as a base of comparison for deposition using other Pt precursors, especially $\mathrm{PtCl}_{4}$. Typical voltammograms are shown in Figure 1. They show two cathodic peaks, one at potentials between -0.75 and $-0.85 \mathrm{~V}$, and another one around $-1.7 \mathrm{~V}$. In the anodic sweep, one anodic peak around -0.95 to $-0.9 \mathrm{~V}$ can be seen, and there are indications for a shoulder at a somewhat lower potential, and two further anodic processes at more positive potentials $(-0.45 \mathrm{~V}$ and close to the upper potential limit). Below $-2.9 \mathrm{~V}$, the ionic liquid starts to decompose, and the electrolyte becomes black.

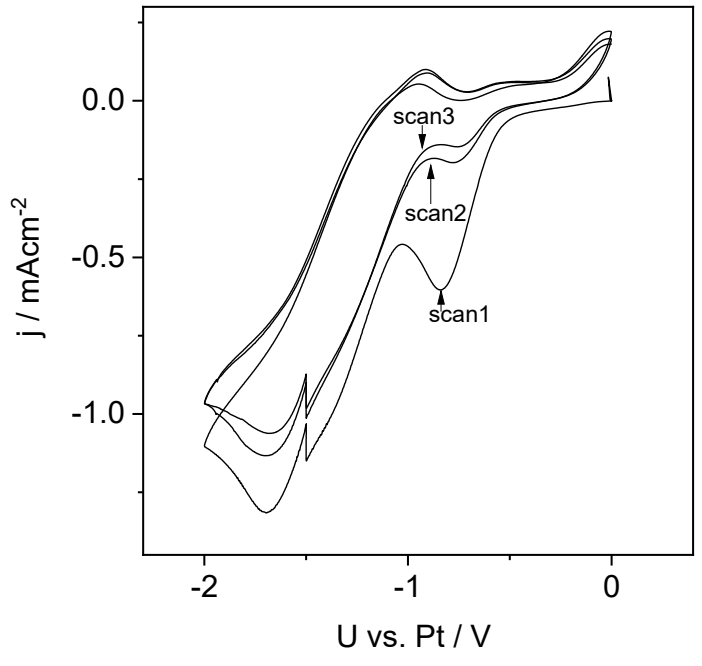

a)

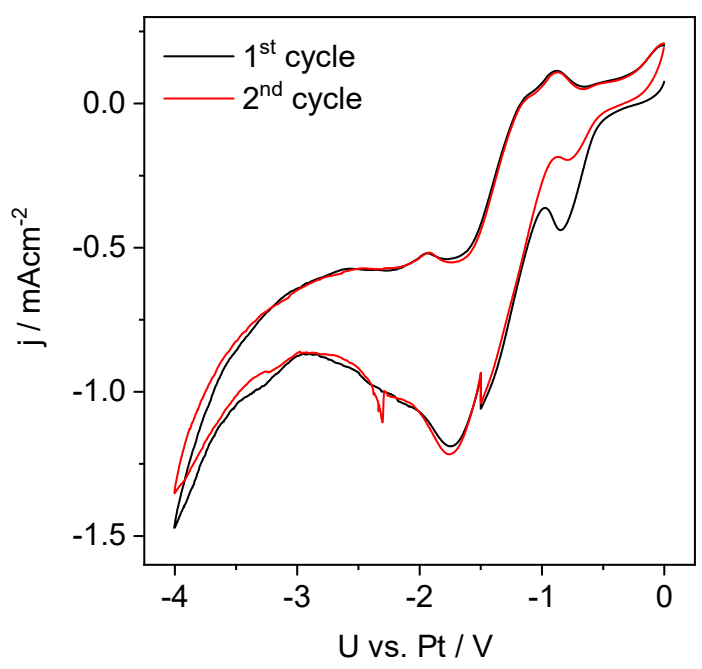

b)

Figure 1. Cyclic voltammograms of BDD in $50 \mathrm{mM} \mathrm{H}_{2} \mathrm{PtCl}_{6}$ in OMP-TFSI at $60^{\circ} \mathrm{C}$; scanrate: $20 \mathrm{mV} \mathrm{s}^{-1}$ between a) 0 and $-2 \mathrm{~V}$ and b) 0 and $-4 \mathrm{~V}$. 
The occurrence of two cathodic peaks has been mentioned in literature, and was identified as a two-step reduction process of the Pt precursor (50). Therefore, a pulsed electrodeposition experiment was carried out using $-1.8 \mathrm{~V}$ as the deposition potential $\mathrm{U}_{\mathrm{ON}}$, for $t_{O N}=1 \mathrm{~s}$ each, and $0 \mathrm{~V}$ as the OFF potential $U_{\text {OFF, for }} t_{\mathrm{OFF}}=4 \mathrm{~s}$ each (cf. Figure $2 \mathrm{a}$ ). The total experiment lasted $30 \mathrm{~min}$. In this particular example, the negative current density first decreased with time, but then increased successively from pulse to pulse. The total charge was negative. Afterwards, the sample was characterized by $\mathrm{CV}$ in sulfuric acid electrolyte (Figure 2b). Clearly, the characteristic features of a Pt CV were obtained.

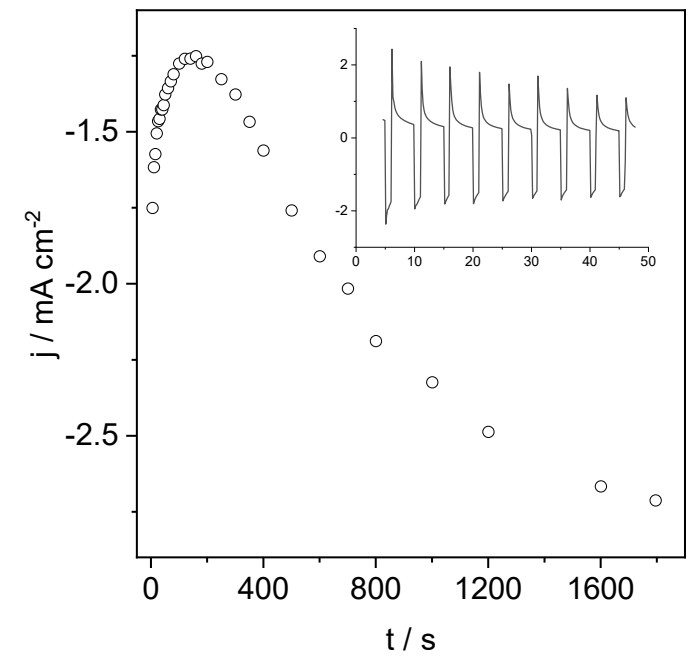

a)

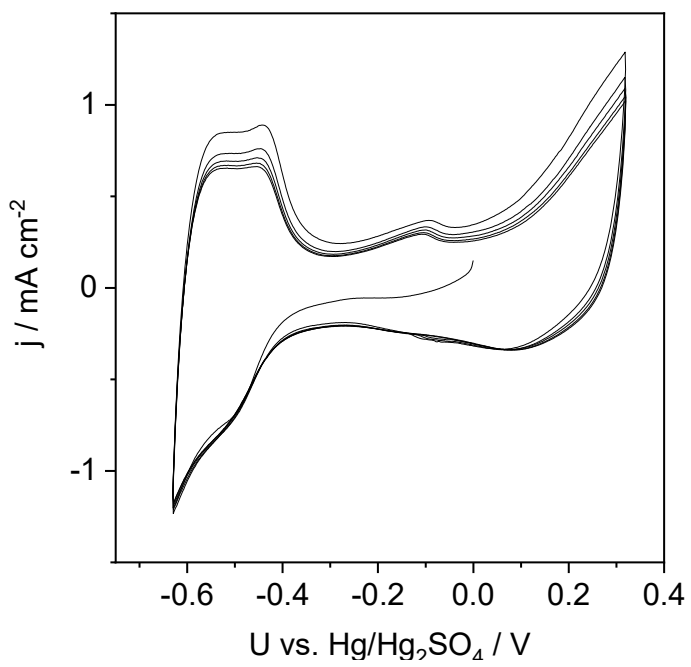

b)

Figure 2. a) $\mathrm{PED}$ on $\mathrm{BDD}$ in $50 \mathrm{mM} \mathrm{H}_{2} \mathrm{PtCl}_{6}$ in $\mathrm{OMP}$-TFSI at $60^{\circ} \mathrm{C}$ at $\mathrm{U}_{\mathrm{ON}}=-1.8 \mathrm{~V}$, ton $=1 \mathrm{~s}, \mathrm{U}_{\mathrm{OFF}}=0 \mathrm{~V}, \mathrm{t}_{\mathrm{OFF}}=4 \mathrm{~s}$. The last measured cathodic current density during selected UON-phases is shown. Inset: Full current-time response during the first $50 \mathrm{~s}$. b) Characterization of sample after PED in aqueous $0.1 \mathrm{M} \mathrm{H}_{2} \mathrm{SO}_{4}$ at $100 \mathrm{mV} \mathrm{s}^{-1}$.

Deposition from $\mathrm{PtCl}_{4}$. Voltammograms obtained in the much less water containing 50 $\mathrm{mM} \mathrm{PtCl}_{4}$ in OMP-TFSI electrolyte are shown in Figure 3a. They show similarities to the behavior seen in $\mathrm{H}_{2} \mathrm{PtCl}_{6}$ based electrolyte. However, the cathodic peak around $-0.75 \mathrm{~V}$ seems to be missing: In the first cycle there is still an increasingly negative current similar to a shoulder in this potential region, while in the second cycle this shoulder is absent as well. Similar to the experiments in $\mathrm{H}_{2} \mathrm{PtCl}_{6}$ based electrolytes, PED experiments were carried out. A typical PED is shown in Figure 3b. Except for short times, the general behavior is qualitatively similar to the one shown in Figure 2a. Both in CV and PED, the obtained current densities are smaller compared to the $\mathrm{H}_{2} \mathrm{PtCl}_{6}$ based electrolyte. The influence of PED parameters on the Pt deposition was studied by a small experimental series in which for each experiment a fresh BDD sample was used. For all samples (CV + PED or PED alone), the presence of Pt was proven by voltammetry in aqueous sulfuric acid electrolyte. Tables I and II summarize the findings for the ECSA determination for both $\mathrm{H}_{2} \mathrm{PtCl}_{6}$ and $\mathrm{PtCl}_{4}$ based electrolytes. 


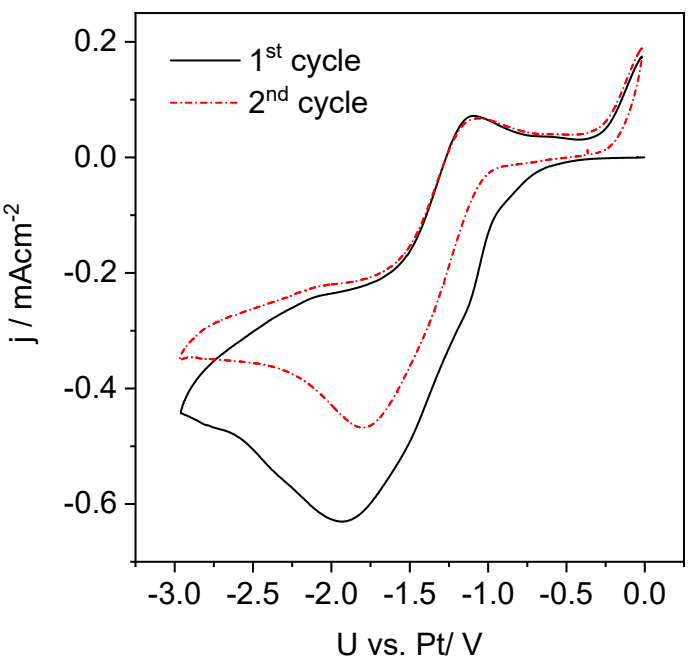

a)

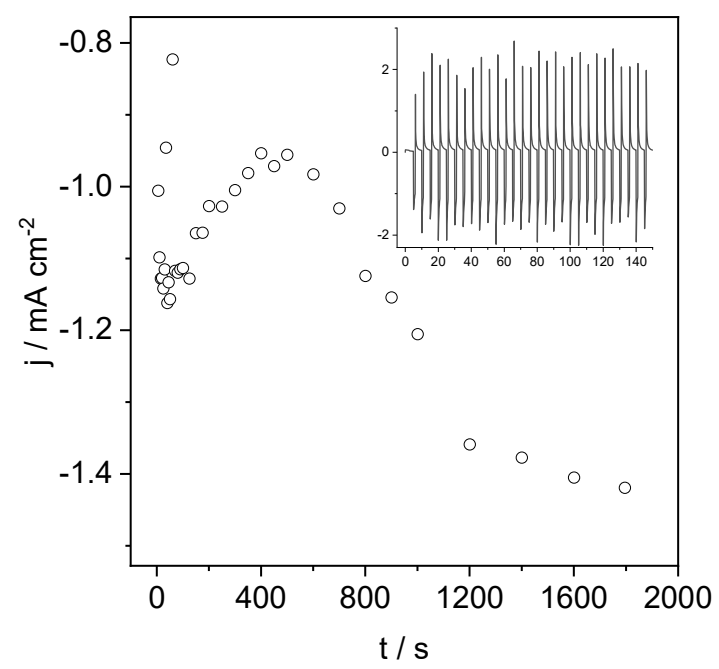

b)

Figure 3. a) Cyclic voltammograms of BDD in $50 \mathrm{mM} \mathrm{PtCl}_{4}$ in OMP-TFSI at $60^{\circ} \mathrm{C}$; scanrate: $20 \mathrm{mV} \mathrm{s}^{-1}$ between 0 and $-3 \mathrm{~V}$. b) PED in the same electrolyte, at $U_{\mathrm{ON}}=-1.6 \mathrm{~V}$, $\mathrm{t}_{\mathrm{ON}}=1 \mathrm{~s}, \mathrm{U}_{\mathrm{OFF}}=0 \mathrm{~V}, \mathrm{t}_{\mathrm{OFF}}=4 \mathrm{~s}, 30 \mathrm{~min}$ total. The last measured cathodic current density during selected $\mathrm{U}_{\mathrm{ON}}-$ phases is shown. Inset: Full current-time response during the first $150 \mathrm{~s}$.

Table I. Pulsed electrodeposition parameters for selected Pt deposition experiments on BDD using either $50 \mathrm{mM} \mathrm{H}_{2} \mathrm{PtCl}_{6}$ or $\mathrm{PtCl}_{4}$ in OMP-TFSI as electrolyte.

\begin{tabular}{ccccccc}
\hline No. & Experiment & $\mathbf{U}_{\text {ON }} / \mathbf{V}$ & ton $/ \mathbf{s}$ & $\mathbf{U}_{\text {OFF }} / \mathbf{V}$ & tofF $/ \mathbf{s}$ & PED duration \\
\hline 1 & $\mathrm{H}_{2} \mathrm{PtCl}_{6}, \mathrm{CV}+\mathrm{PED}$ & -1.8 & 1 & 0 & 4 & $30 \mathrm{~min}$ \\
2 & $\mathrm{PtCl}_{4}, \mathrm{CV}+\mathrm{PED}$ & -1.6 & 1 & 0 & 4 & $30 \mathrm{~min}$ \\
3 & $\mathrm{PtCl}_{4}, \mathrm{PED}$ & -1.6 & 5 & 0 & 20 & $15 \mathrm{~min}$ \\
4 & $\mathrm{PtCl}_{4}, \mathrm{PED}$ & -1.6 & 1 & 0 & 4 & $15 \mathrm{~min}$ \\
5 & $\mathrm{PtCl}_{4}, \mathrm{PED}$ & -1.6 & 5 & 0 & 5 & $15 \mathrm{~min}$ \\
\hline
\end{tabular}

Table II. Sum of charge flown during selected Pt deposition experiments (cf. Table I) obtained by integration of both positive and negative currents $\left(\mathrm{Q}_{\text {total }}\right)$, and cathodic charge (Qcath) obtained only by integration of negative (net reduction) currents. Results from the analysis of the $\mathrm{H}_{\text {UPD }}$ region of subsequent voltammograms recorded in aqueous $0.1 \mathrm{M} \mathrm{H}_{2} \mathrm{SO}_{4}$, capacitive background charge and computed $\mathrm{Pt}$ active surface area (ECSA).

\begin{tabular}{cccccc}
\hline No. & $\mathbf{Q}_{\text {total }} /{\mathbf{C ~} \mathbf{~ c m}^{-2}}^{-2}$ & $\mathbf{Q}_{\text {cath }} / \mathbf{C} \mathbf{~ c m}^{-2}$ & $\begin{array}{c}\text { ECSA integration } \\
\text { range } / \mathbf{V}\end{array}$ & $\begin{array}{c}\text { Capacitive } \\
\text { background } \\
\text { charge } / \mathbf{C ~ c m}^{-2}\end{array}$ & $\begin{array}{c}\text { Pt coverage / } \\
\mathbf{c m}^{2} \mathbf{P t} \mathbf{~ c m}^{-2} \\
\text { geometric area }\end{array}$ \\
\hline 1 & CV: -0.170 & CV: -0.170 & -0.267 to -0.628 & $-7.5 \cdot 10^{-4}$ & 5.62 \\
& PED: -0.187 & PED: -0.934 & & & \\
2 & CV: -0.069 & CV: -0.072 & -0.354 to -0.629 & $-1.1 \cdot 10^{-3}$ & 4.17 \\
& PED: -0.103 & PED: -0.581 & -0.354 to -0.742 & $-1.54 \cdot 10^{-3}$ & 8.91 \\
3 & -0.0746 & -0.199 & -0.275 to -0.628 & $-4.65 \cdot 10^{-4}$ & 2.59 \\
4 & -0.107 & -0.358 & -0.290 to -0.629 & $-7.06 \cdot 10^{-4}$ & 4.09 \\
5 & -0.101 & -0.307 & -0.319 to -0.629 & $-5.05 \cdot 10^{-4}$ & 0.56 \\
\hline
\end{tabular}

As shown in Table II, there is a rough correlation between the cathodic charges during PED and the obtained Pt coverage. The exception is experiment No. 5, where only very little Pt was found. This experiment showed also during PED a continuous decrease in the cathodic current densities with time, different to the curves shown in Figures $2 \mathrm{a}$ and $3 \mathrm{~b}$. 


\section{Electrochemical Quartz Crystal Microbalance Studies on Pt Deposition}

Investigations with the electrochemical quartz microbalance (EQCM) complemented the studies on BDD. EQCM provides additional information about the processes at the electrode surface; especially it permits to draw conclusions of the correlation between electrochemical currents and the occurrence of an actual deposition process. The electrode material on the quartz resonators is gold $(\mathrm{Au})$.

Deposition from Hexachloroplatinic Acid. At room temperature (results not shown), the voltammogram of a $50 \mathrm{mM} \mathrm{H}_{2} \mathrm{PtCl}_{6}$ in OMP-TFSI solution is qualitatively similar to those seen at BDD. In the first cycle, there are again two cathodic peaks at $-0.63 \mathrm{~V}$ and $-1.28 \mathrm{~V}$ and one anodic one at $-0.737 \mathrm{~V}$. The cathodic current density was $-9.09 \cdot 10^{-5} \mathrm{~A}$ $\mathrm{cm}^{-2}$ for the first and $-1.27 \cdot 10^{-4} \mathrm{~A} \mathrm{~cm}^{-2}$ for the second cathodic peak, while the anodic peak current was only $5.9 \cdot 10^{-6} \mathrm{~A} \mathrm{~cm}^{-2}$. From the second cycle on, the cathodic peak at more positive potentials disappeared, and the cathodic and anodic peak currents increased in magnitude compared to the first cycle. Both $f_{R}$ and $w$ changed as function of potential, but the overall $\Delta w$ was more than twice as large compared to $\Delta f_{R}$. Therefore, the Sauerbrey equation was not applicable. Calculation of the derivatives of $\Delta f_{R}$ showed that the electrochemical peak structure is reflected in the EQCM response (cf. results at $60^{\circ} \mathrm{C}$ below).

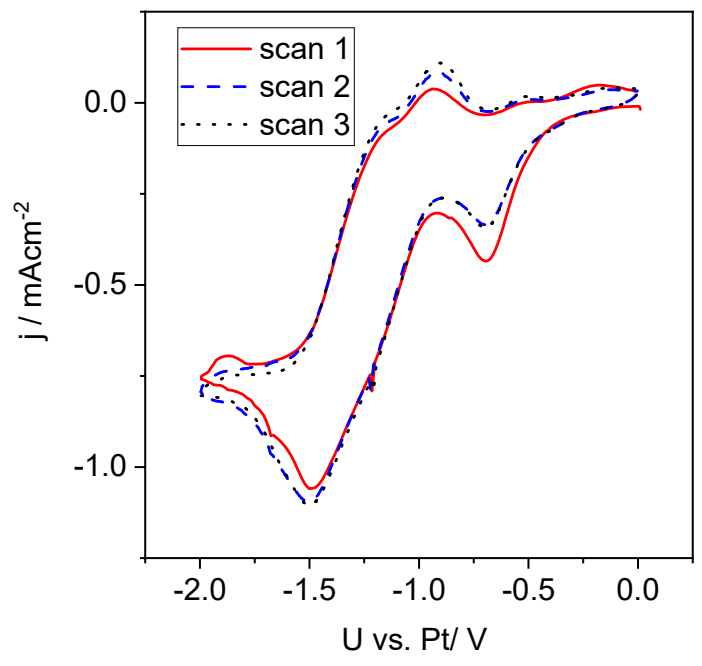

a)

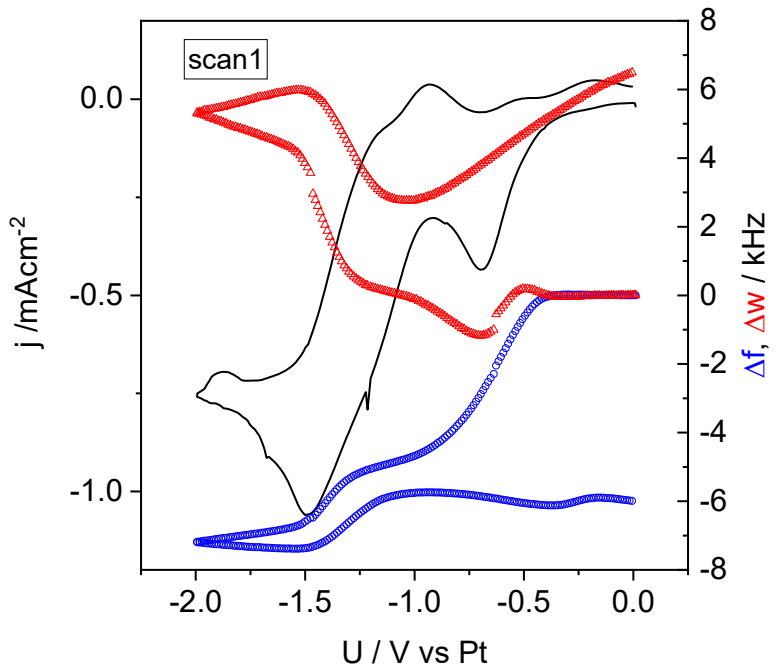

b)

Figure 4. Cyclic voltammogram of Au in $50 \mathrm{mM} \mathrm{H}_{2} \mathrm{PtCl}_{6}$ in OMP-TFSI at $60^{\circ} \mathrm{C}$. Scanrate: $5 \mathrm{mV} \mathrm{s}^{-1}$. a) Voltammograms of the first three cycles. b) Change in resonance frequency (blue circles) and damping (red triangles) during the first cycle.

The general shape of the voltammograms at $60^{\circ} \mathrm{C}$ (cf. Fig. 4a) is similar to those measured at room temperature, but the currents are much larger and the cathodic peak at $-0.69 \mathrm{~V}$ does not disappear in later cycles. Both resonance frequency and damping change during the cycle (Fig. $4 \mathrm{~b}$ ), but the ratio between $\Delta w$ and $\Delta f_{R}$ is at least for more positive potentials smaller compared to the measurements at room temperature. Both $\Delta w$ and $\Delta f_{R}$ do not reach the original values once a cycle is completed, indicating an irreversible change at the electrode surface. In a typical metal electrodeposition experiment with $100 \%$ current efficiency, the recorded frequency change should scale with the mass of deposited metal according to the Sauerbrey equation, and via Faraday's law with the total electrochemical 
charge. The derivative of the frequency with respect to time then should correlate with the electrochemical current. The general correlation between measured currents and $d \Delta f_{R} d t^{-1}$ is demonstrated in Figure 5a. Similar to the measurements on BDD, a PED experiment was carried out as well. Based on the EQCM CV data (cf. discussion section), in this case $\mathrm{U}_{\mathrm{ON}}$ was selected in the potential region of the first cathodic peak. The corresponding current, $\Delta f_{R}$ and $\Delta w$ data are shown in Figure $5 \mathrm{~b} . \Delta f_{R}$ becomes more negative with time, while $\Delta w$ increases. The total change in $\Delta w$ is smaller than the one in $\Delta f_{R}$. The presence of Pt on the surface after the end of the experiments was once more proved by the electrochemical cycling in aqueous $0.1 \mathrm{M} \mathrm{H}_{2} \mathrm{SO}_{4}$. The ECSA value was $5.9 \mathrm{~cm}^{2}$.

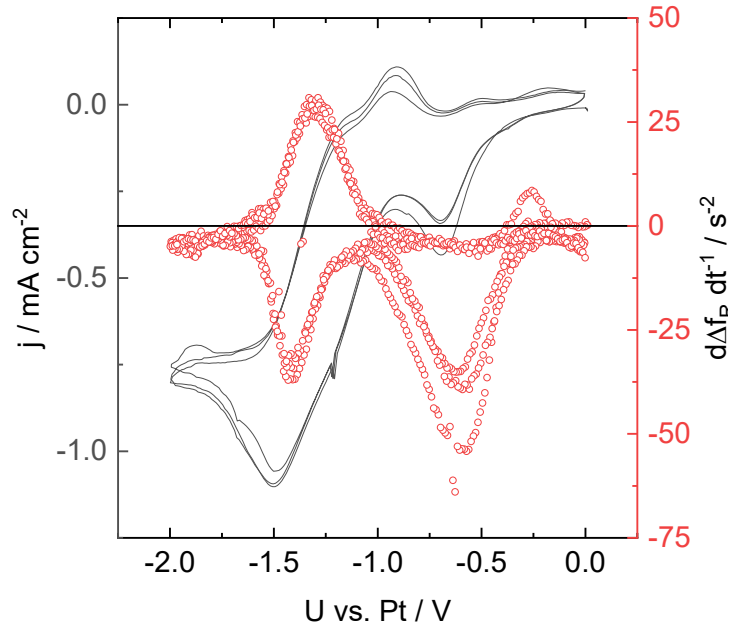

a)

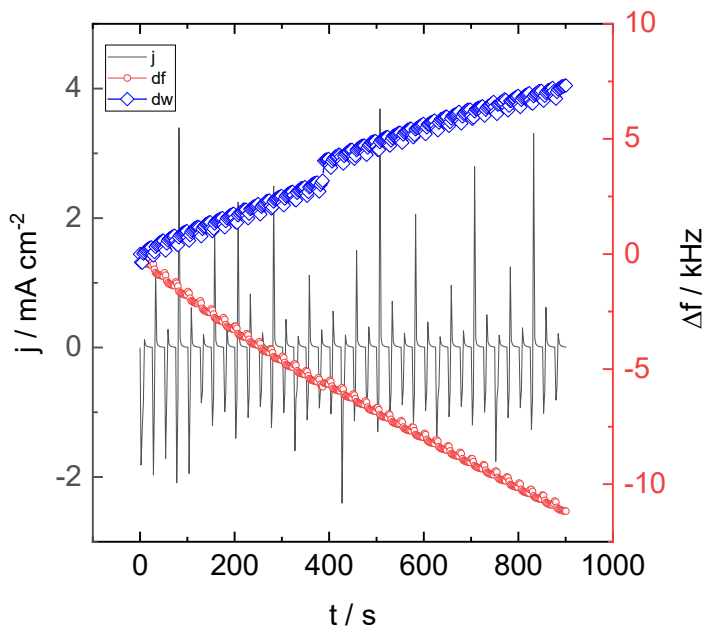

b)

Figure 5. a) Cyclic voltammograms (black lines) of $\mathrm{Au}$ in $50 \mathrm{mM} \mathrm{H}_{2} \mathrm{PtCl}_{6}$ in OMP-TFSI at $60^{\circ} \mathrm{C}$, scanrate: $5 \mathrm{mV} \mathrm{s}^{-1}$, compared to the first time derivative of the change in the EQCM resonance frequency (red circles). b) PED experiment $\left(\mathrm{U}_{\mathrm{ON}}=-0.7 \mathrm{~V}\right.$, toN $=5 \mathrm{~s}$; $\mathrm{U}_{\mathrm{OFF}}=0.0 \mathrm{~V}, \mathrm{t}_{\mathrm{OFF}}=20 \mathrm{~s}$ ): Current density (line), change in resonance frequency (red circles) and damping (blue diamonds).

Deposition from $\mathrm{PtCl}_{4}$. The results using $\mathrm{PtCl}_{4}$ were not so much different from those with $\mathrm{H}_{2} \mathrm{PtCl}_{6}$ even though the currents were smaller by a factor of two. The first cathodic peak appeared in the first voltammetric cycle, but significantly decreased in subsequent cycles. For PED, the deposition potential was selected as $-1.2 \mathrm{~V}$, while all other parameters remained the same as for the $\mathrm{H}_{2} \mathrm{PtCl}_{6}$ based electrolyte. Apart from the first $50 \mathrm{~s}$, the resulting currents were very small, below $10 \mu \mathrm{A} \mathrm{cm}^{-2}$, and did not show significant changes between ON and OFF phase. The ECSA value was $1.28 \mathrm{~cm}^{2}$.

\section{Discussion}

The electrodeposition of Pt from hexachloroplatinic acid reported by us in earlier work (6) for highly oriented pyrolithic graphite (HOPG) as a substrate was reproduced in this work both on BDD and Au substrates. The formation of metallic Pt was unequivocally proven by characterization of the obtained samples in aqueous sulfuric acid. Voltammograms clearly showing the characteristic features of a platinum electrode (57) were obtained. 
The general shape of the deposition voltammograms was close to the earlier measurements on HOPG, at least in the cathodic cycle, revealing two cathodic peaks,

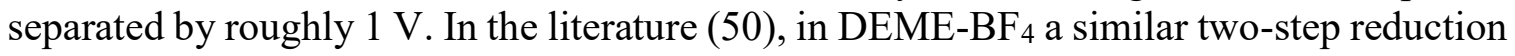
wave was explained by a reduction mechanism involving first the reduction of $\mathrm{Pt}(\mathrm{IV})$ to $\mathrm{Pt}(\mathrm{II})$, and subsequently to $\operatorname{Pt}(0)$. The anodic curve shown in that paper looked however different from our data. During repeated cycling, the first reduction peak in our study often tends to disappear. This may be due to the formation of some passive layer on the surface, and be related to catalytic decomposition of the TFSI ion at lower potentials (58).

Qualitatively similar behavior was also obtained from the $\mathrm{PtCl}_{4}$ precursor that does not contain hydrate water and can be dried at higher temperatures than $\mathrm{H}_{2} \mathrm{PtCl}_{6}$. The peak potentials were similar, but the peak currents were smaller. Often, the first cathodic peak was obtained only in the first cycle or hardly visible at all. For the preparation of larger amounts of $\mathrm{Pt}$ at low $\mathrm{Pt}$ precursor concentrations we decided to carry out pulsed electrodeposition. The ON and OFF potentials (Table I) were chosen under the assumption that the lower peak potential represents the actual Pt formation. The correlation between the charges flown and the estimated ECSA values (Table II) showed that maximizing the cathodic current densities is a suitable strategy for optimization of the procedure. $0 \mathrm{~V}$ as the upper cut-off voltage seems to work. The value for tofF must be chosen larger than ton, as otherwise, the precursor concentration close to the surface will deplete with total deposition time. In these studies, we aimed for large quantities of Pt in order to study the general deposition behavior and to facilitate detection of the Pt. Thus we aimed for $\mathrm{Pt}$ coatings on the substrate. Other deposition protocols are required for the preparation of catalytic nanoparticles of defined size and number density on a substrate. This can be done similar to the observations in aqueous electrolytes, using potentiostatic double pulse deposition techniques (37).

The EQCM experiments were carried out to shed further light on the processes associated with the two reduction peaks seen during the voltammograms. In a typical EQCM experiment, the total resonance frequency shift is the sum of several contributions: Apart from the actual mass increase of the electrode due to the formation of a deposit, these can be contributions from a change in the viscoelastic / viscous properties at the surface and from surface roughness. Experiments at room temperature were difficult to interpret as the damping changes $\Delta w$ were so large, that no more conclusion can be drawn on the gravimetric contribution to $\Delta f_{R}$. At $60^{\circ} \mathrm{C}, \Delta w$ still was large, but less than twice the change in resonance frequency (Figure $4 \mathrm{~b}$ ). Therefore, analysis is possible. One property that changes with temperature is the electrolyte viscosity. Therefore, also effects caused by viscosity changes close to the electrode can be expected to be lower at more elevated temperatures, resulting in a reduced damping increase. Both cathodic peaks and the first anodic shoulder (not the anodic peak) shown in Figure 5a have corresponding peaks in the $\mathrm{d} \Delta f_{R} d t^{-1}$ plot. The peak potentials for the $\mathrm{d} \Delta f_{R} d t^{-1}$ peak couple at lower potentials are only separated by $100 \mathrm{mV}$. In addition, anodic and cathodic peak heights (measured with respect to the slightly negative base line) are basically the same. This points to a rather reversible electrochemical redox process. If this redox process was due to the $\mathrm{Pt}(\mathrm{II}) / \mathrm{Pt}(0)$ redox couple, then one would not expect to find any metallic Pt on the surface after the end of the experiments. Also, there is the question of speciation: if $\mathrm{Pt}$ metal is reduced from $\left[\mathrm{PtCl}_{4}\right]^{2-}$ releasing the four chloride ions into the electrolyte, then these might diffuse away and may no longer be available during (potential) Pt dissolution. 
Faradays law permits to correlate the mass changes on the electrode with the electric charge measured in the experiment, as - at $100 \%$ efficiency for a single step reaction - the ratio of areal mass change $\Delta m$ and charge density $\Delta q$ should be equal to $M / z F$, where $M$ is the molar mass of the deposited species, $z$ the number of electrons transferred and $F$ Faradays constant. For direct Pt deposition from $\mathrm{Pt}(\mathrm{IV})$, one would expect a ratio $\Delta \mathrm{m} / \Delta q$ $=5.055 \cdot 10^{-4} \mathrm{~g} \mathrm{C}^{-1}$. For Pt deposition from Pt(II), $0.00101 \mathrm{~g} \mathrm{C}^{-1}$ would be expected instead. For reduction of $\mathrm{PtCl}_{4}$ to $\mathrm{PtCl}_{2}$, which is not that well soluble in OMP-TFSI and thus could precipitate on the electrode, $0.00138 \mathrm{~g} \mathrm{C}^{-1}$ is expected. Figure 6 shows a mass-charge plot calculated via the Sauerbrey equation from the $\Delta f_{R}$ data. Due to the strong damping changes, the numbers for the mass change in this plot are larger than the true ones, therefore one will overestimate $\Delta m / \Delta q$. The thick line is $\Delta m$ while the dashed line represents the electrode potentials. The numbers shown for the first cycle identify the different regions in the $\mathrm{CV}$ from Figure 5: "1" corresponds to the potential region from 0 to $-1 \mathrm{~V}$ where the first reduction peak prevails, " $2 \mathrm{r}$ " from -1.1 to $-1.5 \mathrm{~V}$, which corresponds to the right half of the large reduction peak, " 21 " from $-1.5 \mathrm{~V}$ to the lower potential limit, and 3 to the anodic sweep between $-2 \mathrm{~V}$ and $-1.5 \mathrm{~V}$.

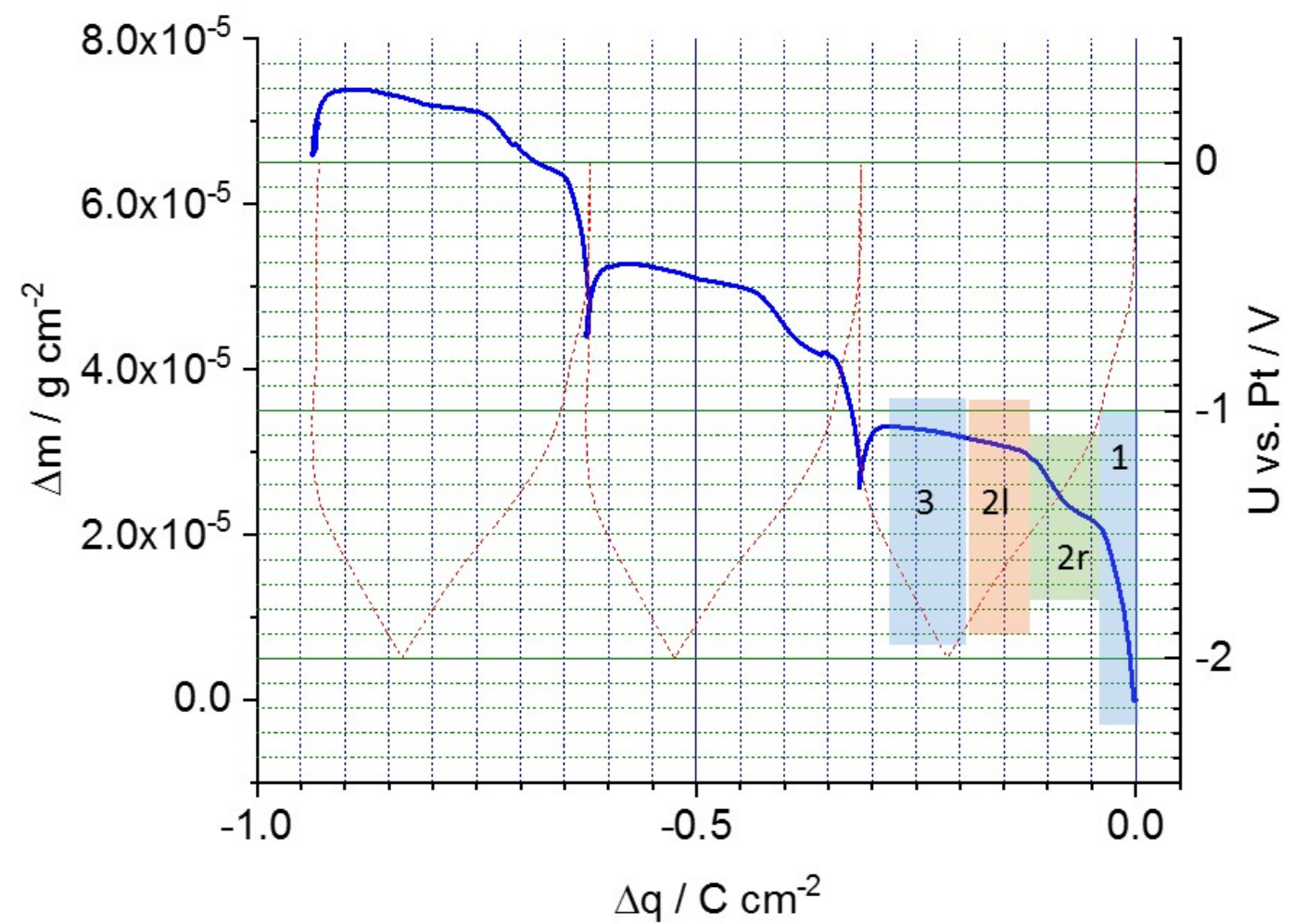

Figure 6. Mass-charge plot for the EQCM data shown in Figure 5. The thick solid line shows the mass calculated without correction from Sauerbrey's equation. The red dashed line provides the corresponding potential. For regions in the first voltammetric cycle are marked, corresponding to the first cathodic peak ("1"), the right half of the second cathodic peak (" $2 r$ "), the left half of that peak (" 21 "), and the initial region of the anodic sweep (" 3 ").

Using this plot, linear regressions were carried out to determine $\Delta m / \Delta q$ in the different regions of the voltammograms. The results are given in Table III. In addition, a corrected $\Delta f_{R}$ was determined by adding half of the damping change to the value of the resonance frequency. The reason for this attempt of a correction is that sometimes there is a strong correlation between the damping and the resonance frequency changes for non-gravimetric 
contributions with $\Delta w=2 \cdot \Delta f_{R}$. Examples are the change of the admittance curve upon immersion of a quartz in liquid (Gordon-Kanazawa-Mason equation (59)) or some equations concerning the influence of electrode roughness (60). In the current work, the reduced damping at higher temperatures is indicative of a viscosity effect.

The results in Table III actually show that values consistent with Pt deposition are only obtained for the first reduction peak. The mass changes associated with the second reduction peak are very small, especially after correction for the damping change. Therefore, the observed changes in the resonance frequency in the region of the second cathodic peak are probably mainly related to a change in viscosity close to the surface, and not to Pt deposition - which still can occur as a side reaction with low current efficiency. Similar results were obtained from the data analysis when using $\mathrm{PtCl}_{4}$. Also for the PED experiment shown in Figure $5 \mathrm{~b}$ at a deposition potential of $-0.7 \mathrm{~V}$ was consistent with $\mathrm{Pt}$ metal deposition. However, the sampling rate in this experiment was rather low so that the charge obtained by integration of the current density has a larger uncertainty.

Table III. $\Delta m / \Delta q$ values obtained from the data shown in Figure 6. In addition, corrected values are provided, where before application of the Sauerbrey equation $\Delta w / 2$ was added to the $\Delta f_{R}$. values.

\begin{tabular}{cccc}
\hline Region & Potential range $/ \mathbf{V}$ & $\boldsymbol{\Delta} \boldsymbol{m} / \boldsymbol{\Delta q}$ & $\boldsymbol{\Delta \boldsymbol { m }}$ corr $/ \boldsymbol{\Delta q}$ \\
\hline 1 & -0.46 to -0.56 & -0.00123 & -0.00134 \\
1 & -0.686 to -0.84 & $-4.428 \mathrm{E}-4$ & $-3.55 \mathrm{E}-4$ \\
$2 \mathrm{r}$ & -1.33 to -1.44 & $-1.605 \mathrm{E}-4$ & $-3.25 \mathrm{E}-6$ \\
21 & -1.57 to -1.84 & $-2.33 \mathrm{E}-5$ & $3.9 \mathrm{E}-6$ \\
\hline
\end{tabular}

Not all aspects are currently understood: The irreversible contributions to both $\Delta f_{R}$ and $\Delta w$ are mainly associated with reactions taking place at potentials between $0 \mathrm{~V}$ and $-1 \mathrm{~V}$. Some of these might be related to surface roughening due to $\mathrm{Pt}$ deposition. However, while $\Delta f_{R}$ becomes constant during the anodic sweeps when approaching the upper potential limit, $\Delta w$ shows an irreversible increase there as well. The cause of that behavior is unclear. In addition, it is not clear which electrochemical reaction is connected to the nearly reversible redox process at lower potentials, what the mechanism behind the disappearance of the reduction peak at $\sim-0.7 \mathrm{~V}$ especially for $\mathrm{PtCl}_{4}$ precursors is, and what the consequences for further Pt deposition are.

\section{Conclusions}

Metallic platinum has been successfully deposited both from solutions of $\mathrm{H}_{2} \mathrm{PtCl}_{6}$ and $\mathrm{PtCl}_{4}$ in OMP-TFSI. The voltammograms show two reduction peaks. The one at higher potentials often disappears in later cycles due to a passivation process. However, EQCM data indicate that this peak corresponds to actual Pt deposition. The electrochemical reduction process at lower potentials seems to lead to a reversible viscosity increase in front of the electrode. The actual electrode reaction associated with this process is not yet known. The actual co-deposition of $\mathrm{Pt}$ and $\mathrm{Gd}$ can be based on $\mathrm{PtCl}_{4}$ as the precursor. However, an ionic liquid suitable to deposit both metals needs to be identified. A mixture of e.g. OMP TFSI (where Pt works) and BMP DCA from which Gd can be deposited, might provide a solution. 


\section{Acknowledgments}

The project leading to this paper has received funding from the Fuel Cells and Hydrogen 2 Joint Undertaking under grant agreement No 700127. This Joint Undertaking receives support from the European Union's Horizon 2020 Research and Innovation Programme and Hydrogen Europe and Hydrogen Europe Research. The support of Prof. U. Heiz (Chemistry Department, Technical University of Munich) and Prof. A. Knoll (Institute of Informatics VI, Technical University of Munich) and the use of their facilities

are appreciated. We thank Prof. Holger Fritze (Clausthal University of Technology) for providing a software to fit the NA data automatically.

\section{References}

1. O. Gröger, H. A. Gasteiger, and J.-P. Suchsland, J. Electrochem. Soc., 162, A2605 (2015).

2. H. A. Gasteiger, S. S. Kocha, B. Sompalli, and F. T. Wagner, Appl. Catal., B, 56, 9 (2005).

3. A. U. Nilekar, and M. Mavrikakis, Surf. Sci., 602, L89 (2008).

4. J. K. Norskov, J. Rossmeisl, A. Logadottir, L. Lindqvist, J. R. Kitchin, T. Bligaard, and H. Jonsson, J. Phys. Chem. B, 108, 17886 (2004).

5. U. A. Paulus, T. J. Schmidt, H. A. Gasteiger, and R. J. Behm, J. Electroanal. Chem., 495, 134 (2001).

6. L. Asen, W. Ju, E.Mostafa, S. Martens, U. Heiz, U. Stimming, and O. Schneider, ECS Trans., 75 (15), 323 (2016).

7. M. K. Debe, Nature, 486, 43 (2012).

8. F. Calle-Vallejo, J. Tymoczko, V. Colic, Q. H. Vu, M. D. Pohl, K. Morgenstern, D. Loffreda, P. Sautet, W. Schuhmann, and A. S. Bandarenka, Science, 350, 185 (2015).

9. I. Jiménez-Morales, S. Cavaliere, D. Jones, and J. Rozière, Phys. Chem. Chem. Phys., 20, 8765 (2018).

10. L. Perini, C. Durante, M. Favaro, V. Perazzolo, S. Agnoli, O. Schneider, G. Granozzi, and A. Gennaro, ACS Appl. Mater. Interfaces, 7, 1170 (2015).

11. Z. Chen, D. Higgins, A. Yu, L. Zhang, and J. Zhang, Energy Environ. Sci., 4, 3167 (2011).

12. M. S. Çögenli, S. Mukerjee, and A. B. Yurtcan, Fuel Cells, 15, 288 (2015).

13. J. K. Dombrovskis, and A. E. C. Palmqvist, Fuel Cells, 16, 4 (2016).

14. M. Shao, Q. Chang, J.-P. Dodelet, and R. Chenitz, Chem. Rev., 116, 3594 (2016).

15. A. Morozan, B. Jousselme, and S. Palacin, Energy Environ. Sci., 4, 1238 (2011).

16. N. Ramaswamy, U. Tylus, Q. Jia, and S. Mukerjee, J. Am. Chem. Soc., 135, 15443 (2013).

17. J. Tian, A. Morozan, M. T. Sougrati, M. Lefèvre, R. Chenitz, J.-P. Dodelet, D. Jones, and F. Jaouen, Angew. Chem., 125, 7005 (2013).

18. J. Greeley, I. E. L. Stephens, A. S. Bondarenko, T. P. Johansson, H. A. Hansen, T. F. Jaramillo, J. Rossmeisl, I. Chorkendorff, and J. K. Nørskov, Nat. Chem., 1, 552 (2009).

19. V. Stamenkovic, B. S. Mun, K. J. J. Mayrhofer, P. N. Ross, N. M. Markovic, J. Rossmeisl, J. Greeley, and J. K. Nørskov, Angew. Chem., Int. Ed., 45, 2897 (2006). 
20. I. E. L. Stephens, A. S. Bondarenko, L. Bech, and I. Chorkendorff, ChemCatChem, 4, 341 (2012).

21. I. E. L. Stephens, A. S. Bondarenko, U. Gronbjerg, J. Rossmeisl, and I. Chorkendorff, Energy Environ. Sci., 5, 6744 (2012).

22. I. E. L. Stephens, A. S. Bondarenko, F. J. Perez-Alonso, F. Calle-Vallejo, L. Bech, T. P. Johansson, A. K. Jepsen, R. Frydendal, B. P. Knudsen, J. Rossmeisl, and I. Chorkendorff, J. Am. Chem. Soc., 133, 5485 (2011).

23. C. Wang, N. M. Markovic, and V. R. Stamenkovic, ACS Catal., 2, 891 (2012).

24. A. F. Pedersen, E. T. Ulrikkeholm, M. Escudero-Escribano, T. P. Johansson, P. Malacrida, C. M. Pedersen, M. H. Hansen, K. D. Jensen, J. Rossmeisl, D. Friebel, A. Nilsson, I. Chorkendorff, and I. E. L. Stephens, Nano Energy, 29, 249 (2016).

25. E. T. Ulrikkeholm, A. F. Pedersen, U. G.Vej-Hansen, M. Escudero-Escribano, I. E. L. Stephens, D. Friebel, A. Mehta, J. Schiøtz, R. K. Feidenhansl, A. Nilsson, and I. Chorkendorff, Surf. Sci., 652, 114 (2016).

26. M. Escudero-Escribano, A. Verdaguer-Casadevall, P. Malacrida, U. Grønbjerg, B. P. Knudsen, A. K. Jepsen, J. Rossmeisl, I. E. L. Stephens, and I. Chorkendorff, J. Am. Chem. Soc., 134, 16476 (2012).

27. P. Hernandez-Fernandez, F. Masini, D. N. McCarthy, C. E. Strebel, D. Friebel, D. Deiana, P. Malacrida, A. Nierhoff, A. Bodin, A. M. Wise, J. H. Nielsen, T. W. Hansen, A. Nilsson, I. E. L. Stephens, and I. Chorkendorff, Nat. Chem., 6, 732 (2014).

28. T. P. Johansson, E. T. Ulrikkeholm, P. Hernandez-Fernandez, M. EscuderoEscribano, P. Malacrida, I. E. L. Stephens, and I. Chorkendorff, Phys. Chem. Chem. Phys., 16, 13718 (2014).

29. T. P. Johansson, E. T. Ulrikkeholm, P. Hernandez-Fernandez, P. Malacrida, H. A. Hansen, A. S. Bandarenka, J. K. Nørskov, J. Rossmeisl, I. E. L. Stephens, and I. Chorkendorff, Top. Catal., 57, 245 (2014).

30. P. Malacrida, M. Escudero-Escribano, A. Verdaguer-Casadevall, I. E. L. Stephens, and I. Chorkendorff, J. Mater. Chem. A, 2, 4234 (2014).

31. A. Velázquez-Palenzuela, F. Masini, A. F. Pedersen, M. Escudero-Escribano, D. Deiana, P. Malacrida, T. W. Hansen, D. Friebel, A. Nilsson, I. E. L. Stephens, and I. Chorkendorff, J. Catal., 328, 297 (2015).

32. M. Escudero-Escribano, P. Malacrida, M. H. Hansen, U. G. Vej-Hansen, A. Velázquez-Palenzuela, V. Tripkovic, J. Schiøtz, J. Rossmeisl, I. E. L. Stephens, and I. Chorkendorff, Science, 352, 73 (2016).

33. M. K. Carpenter, T. E. Moylan, R. S. Kukreja, M. H. Atwan, and M. M. Tessema, J. Am. Chem. Soc., 134, 8535 (2012).

34. X. Huang, Z. Zhao, L. Cao, Y. Chen, E. Zhu, Z. Lin, M. Li, A. Yan, A. Zettl, Y. M. Wang, X. Duan, T. Mueller, and Y. Huang, Science, 348, 1230 (2015).

35. J. Fichtner, B. Garlyyev, S. Watzele, H. A. El-Sayed, J. N. Schwämmlein, W.-J. Li, F. M. Maillard, L. Dubau, J. Michalička, J. M. Macak, A. Holleitner, and A. S. Bandarenka, ACS Appl. Mater. Interfaces, 11, 5129 (2019).

36. T. Brülle, and U. Stimming, J. Electroanal. Chem., 636 (1-2), 10 (2009).

37. T. Brülle, A. Denisenko, H. Sternschulte, and U. Stimming, Phys. Chem. Chem. Phys., 13, 12883 (2011).

38. J. V. Zoval, J. Lee, S. Gorer, and R. M. Penner, J. Phys. Chem. B, 102, 1166 (1998).

39. S. Legeai, S. Diliberto, N. Stein, C. Boulanger, J. Estager, N. Papaiconomou, and M. Draye, Electrochem. Commun., 10, 1661 (2008). 
40. A. Ispas, M. Buschbeck, S. Pitula, A. Mudring, M. Uhlemann, A. Bund, and F. Endres, ECS Trans., 16 (45), 119 (2009).

41. A. Kurachi, M. Matsumiya, K. Tsunashima, and S. Kodama, J. Appl. Electrochem., 42, 961 (2012).

42. Q. B. Zhang, C. Yang, Y. X. Hua, Y. Li, and P. Dong, Phys. Chem. Chem. Phys., 17, 4701 (2015).

43. F. Endres, ChemPhysChem, 3, 144 (2002).

44. T. Carstens, A. Ispas, N. Borisenko, R. Atkin, A. Bund, and F. Endres, Electrochim. Acta, 197, 374 (2016).

45. R. Atkin, N. Borisenko, M. Druschler, F. Endres, R. Hayes, B. Huber, and B. Roling, J. Mol. Liq., 192, 44 (2014).

46. F. Endres, N. Borisenko, S. Z. E. Abedin, R. Hayes, and R. Atkin, Faraday Discuss., 154, 221 (2012).

47. F. Endres, O. Hoefft, N. Borisenko, L. H. Gasparotto, A. Prowald, R. Al-Salman, T. Carstens, R. Atkin, A. Bund, and S. Zein El Abedin, Phys. Chem. Chem. Phys., 12, 1724 (2010).

48. R. Hayes, N. Borisenko, B. Corr, G. B. Webber, F. Endres, and R. Atkin, Chem. Commun., 48, 10246 (2012).

49. P. He, H. Liu, Z. Li, and J. Li, J. Electrochem. Soc., 152, E146 (2005).

50. D. Zhang, W. C. Chang, T. Okajima, and T. Ohsaka, Langmuir, 27, 14662 (2011).

51. H.-Y. Huang, C.-J. Su, C.-L. Kao, and P.-Y. Chen, J. Electroanal. Chem., 650, 1 (2010).

52. P. Yu, Q. Qian, X. Wang, H. Cheng, T. Ohsaka, and L. Mao, J. Mater. Chem., 20, 5820 (2010).

53. L. Asen, S. Martens, U. Heiz, A. C. Knoll, and O. Schneider, ECS Trans., 86 (13), 475 (2018).

54. G. Sauerbrey, Z. Phys., 155, 206 (1959).

55. A. Glidle, A. R. Hillman, and S. Bruckenstein, J. Electroanal. Chem., 318, 411 (1991).

56. S. Martens, L. Asen, G. Ercolano, F. Dionigi, C. Zalitis, A. Hawkins, A. Martinez Bonastre, L. Seidl, A. C. Knoll, J. Sharman, P. Strasser, D. Jones, and O. Schneider, J. Power Sources, 392, 274 (2018).

57. V. Climent, and J. M. Feliu, J. Solid State Electrochem., 15, 1297 (2011).

58. M. Tulodziecki, J. M. Tarascon, P. L. Taberna, and C. Guery, Electrochem. Commun., 77, 128 (2017).

59. K. Kanazawa, and J. G. Gordon II, Anal. Chim. Acta, 175, 99 (1985).

60. L. Daikhin, E. Gileadi, G. Katz, V. Tsionsky, M. Urbakh, and D. Zagidulin, Anal. Chem., 74, 554 (2002). 